\title{
Translating hands-on activities to virtual resources for broader scientific engagement
}

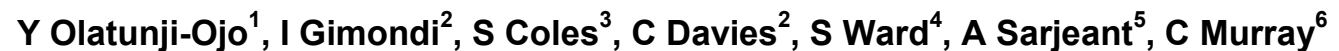 \\ ${ }^{1}$ The Cambridge Crystallographic Data Centre, Oakland, CA, ${ }^{2}$ The Cambridge Crystallographic \\ Data Centre, Cambridge, United Kingdom, ${ }^{3}$ National Crystallography Service, School of \\ Chemistry, University of Southampton, Southhampton, United Kingdom, ${ }^{4}$ CCDC, ${ }^{5}$ Bristol-Myers \\ Squibb, ${ }^{6}$ Diamond Light Source, Harwell Campus, Didcot, United Kingdom \\ yojo@ccdc.cam.ac.uk
}

Educating the public about crystallography and structural chemistry is part of the charitable mission of the Cambridge Crystallographic Data Centre (CCDC). We continue to fulfill this mission through involvement in scientific festivals, but the restrictions placed on public gatherings due to the ongoing pandemic has affected how we at the CCDC conduct these outreach activities. As some of the hands-on scientific events we had lined up were cancelled, we have created online resources and guides based on the planned activities. This talk will highlight some of the outreach projects we have converted to virtual, interactive activities and how we have engaged a community of scientists and non-scientists. We will also share our extension of the International Year of the Periodic Table (IYPT, 2019) through crystal structures which began as an online project to educate the public about the elements through crystals, and has been transformed into an educational card game.

Acta Cryst. (2020). A76, a124 